\title{
The Bioeconomist
}

\author{
Jan Lask, Jan Maier, Boris Tchouga, \\ and Ricardo Vargas-Carpintero
}

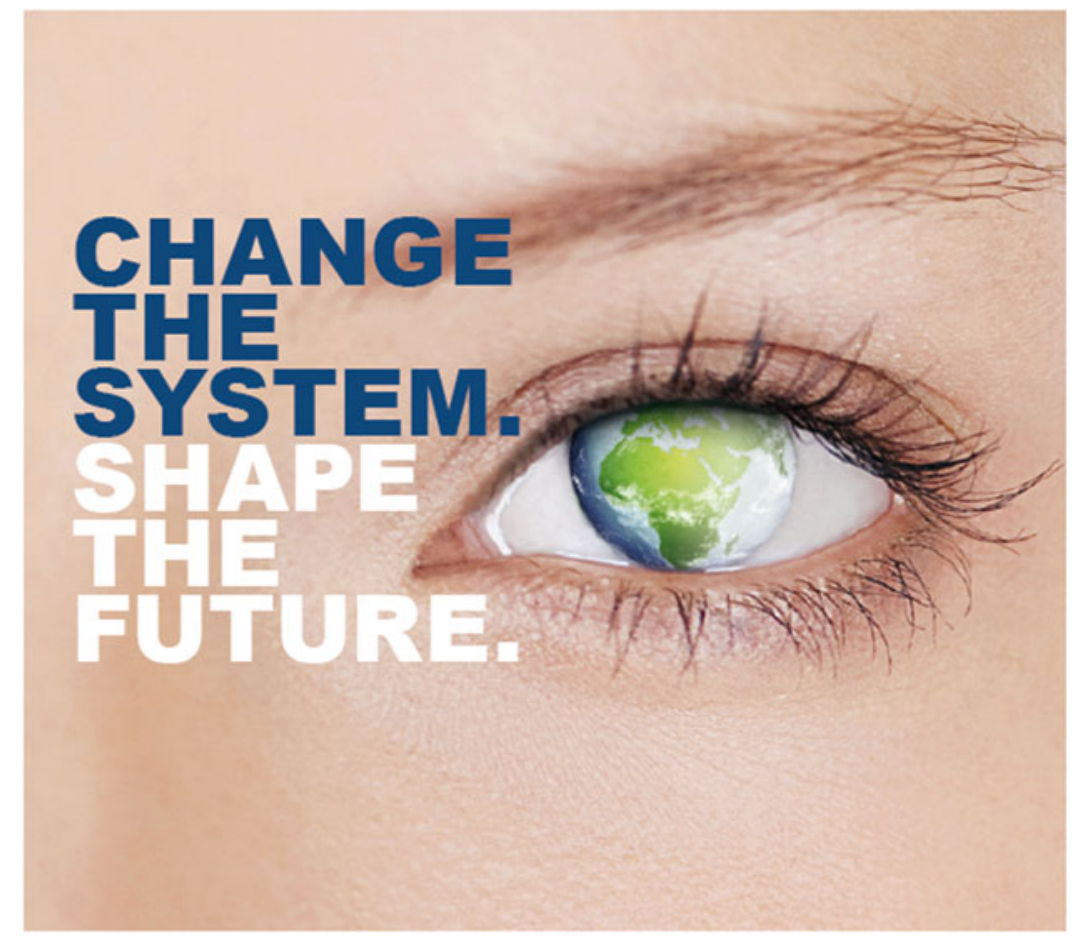

(C) University of Hohenheim/unger + kreative strategen $\mathrm{GmbH}$

J. Lask $(\bowtie)$

MSc Bioeconomy Program, Faculty of Natural Sciences, University of Hohenheim, Stuttgart, Germany

e-mail: Jan.Lask@uni-hohenheim.de

J. Maier

MSc Bioeconomy Program, Faculty of Agricultural

Sciences, University of Hohenheim, Stuttgart, Germany

e-mail: Jan.Maier@uni-hohenheim.de

\section{B. Tchouga $\bullet$ R. Vargas-Carpintero}

MSc Bioeconomy Program, Faculty of Business,

Economics and Social Sciences, University of

Hohenheim, Stuttgart, Germany

e-mail: boris_bonal.tchouga_baho@uni-hohenheim.de; ricardo.vargas@uni-hohenheim.de 


\begin{abstract}
The transition towards a bioeconomy in a challenging and complex environment requires substantial interaction and collaboration between different players on various levels. In this chapter, the concept of a bioeconomy professional is discussed. This actor provides an integrative and connecting role for which the development of basic and key competences is required. The concept of T-shaped profiles, built up from disciplinary expertise and the ability to integrate different disciplines and players holistically, is considered an outstanding feature of bioeconomists. To achieve such profiles, interdisciplinary approaches and new learning environments are required during education process. Bioeconomists have relevant roles in all different stages of the value chain as well as in initially setting them up. Finally, various opinions of experts in bioeconomy fields are presented to get an overview of the potential career opportunities for such professionals.
\end{abstract}

\title{
Keywords
}

T-shaped profile - Collaboration - Mental model - Interdisciplinary competence $\bullet$ Problem-oriented learning $\bullet$ Bioeconomy professional

\section{Learning Objectives}

After studying this chapter, you should:

- Understand the importance of the T-shaped profile in the context of bioeconomy.

- Recognise the basic and key competences of a bioeconomist and its relevant role as collaboration catalyst.

- Realise the benefit of learning in an interdisciplinary environment supported by integrative methods.

\subsection{Wicked Problems and Collaboration}

The socioecological challenges with which present and future generations are faced at all levels (climate change, food security, poverty alleviation, energy supply, etc.) are highly complex and multidimensional. They demand a special interaction between the players involved to achieve the best solutions. Such challenges are referred to as "wicked problems" (see Chap. 4). These differ from "tame problems" in that they cannot be addressed using the linear logic of conventional rationality or understood through quantitative and objective information alone (Innes and Booher 2016). Pacanowsky (1995) explains that whereas tame problems can be solved by thinking "inside the box", wicked problems force the solvers to think "outside the box". Dentoni and Bitzer (2015) affirm that individual actions have limited impact due to coordination failures, and therefore "wicked problems require collective action across societal sectors to generate impactful, transformative change of organizations and systems". The approach to wicked problems requires a different strategy and logic than those usually applied to tame problems. Innes and Booher (2016) argue that a different kind of rationality, a so-called collaborative rationality "built on collaborative dialogue and multifaceted information", is needed to deal with wicked problems. This requires the integration of various views and perspectives under a "systems approach". This type of approach is 
recommended for the formulation and solution of wicked problems (Rittel and Webber 1973). However, rather than being solved, wicked problems are addressed through effective solutions based on the definition of the problem (Pacanowsky 1995). A collaborative dialogue that engages diverse stakeholders' values, knowledge and perspectives contributes to the reframing of untamed problems, rethinking and defining realistic goals and identifying possible solutions through the emergence of innovation (Innes and Booher 2016; Head and Xiang 2016). Innes and Booher (2016) describe the need for planners, who are professionals in setting up, supporting and performing participative processes, and who have the role of active facilitators, following a collaborative rational approach to solving wicked problems.

\section{A Renewed Role of Science}

Seeing wicked challenges through systemic lenses modifies the role of science in society, from a disciplinary to more interdisciplinary, participative and collaborative one. According to various scholars, including Schneidewind et al. (2016) and Batie (2008), the role of science and what society demands of science have changed in the last decades, due to the emergent importance of sustainable development and the need to tackle socioecological problems. Polk (2015) argues that "the role of science is seen as evolving to support more contextualized research processes where the participation and collaboration of different stakeholders and users is central to the ability of the research to create socially relevant and scientifically reliable knowledge", which could contribute to societal change. Schneidewind et al. (2016) depict this new vision of science as one that "does not only observe and describe societal transformation processes, but rather initiates and catalyzes them" (Schneidewind et al. 2016, p. 6). This new role of science is built on the idea of interaction and participation to co-produce knowledge, integrating scientists and non-scientists and using different forms of knowledge, perspectives and experiences to address real-life problems (Polk 2015). Polk uses the term "transdisciplinary co-production" as a research approach that includes practitioners and researchers who interact along the knowledge production process starting with the joint problem formulation.

This new role of science triggers the need for new scientists who play a central role as catalysts, managing and conducting more contextualised research using collaborative and participatory frameworks. Thus, collaboration emerges as a common vision, central for the resolution of wicked problems as well, which demands the active leadership of professionals to enable the interaction among stakeholders and to create participatory solutions to specific challenges. In this chapter, a newly emerging professional, the bioeconomist, is introduced and described as that catalyser and enabler of collaboration for the transition from a fossilbased economy to a bioeconomy, a systemic shift that involves multiple complex challenges, goals and agents. Therefore, bioeconomy professionals are expected to be specialised in one field but also able to understand the scientific language of associated disciplines. Furthermore, the increase focus on innovation and interdisciplinary teamwork has created new student profile expectation to deal with global challenges and find sustainable solutions. In this regard, the formation and development of special competences through inter- and transdisciplinary learning is fundamental.

\subsection{Professionals for the Bioeconomy}

\section{Competences}

The concept of competences supports the description of professional profiles. It aims to conceptualise abilities and thus provides an explicit and commonly shared framework (Wiek et al. 2011).

The Organisation for Economic Co-operation and Development (OECD) describes 
competences as the ability to meet complex demands, by drawing on and mobilising psychological resources (including skills and attitudes) in a particular context (Ananiadou and Claro 2009; OECD 2005). For example, the ability to collaborate effectively in an interdisciplinary team is a competence that relies on an individual's capacity to understand different scientific languages (knowledge) and the attitude he or she has towards other team members. Skills are designated as the ability to use one's knowledge with relative ease to perform relatively simple tasks, while knowledge is defined as the facts or ideas acquired by study, investigation, observation or experience and refers to a body of information that is understood (OECD 2000).

The fulfilment of complex tasks goes beyond the scope of skills and knowledge but also entails the strategies and routines needed to apply the knowledge and skills, including the proper emotions and attitude and the effective management of these components. The development of competences depends both on the educational institutions (schools) attended by an individual and supplementary sociocultural environment such as family and friends (Rychen and Salganik 2000). Multiple sets of competences have been compiled by various international organisations and scientists. For instance, the World Economic Forum (2015) has elaborated an overview of basic competences required in the twenty-first century resulting from the interaction between skills and attitudes (Fig. 12.1).

Basic competences are required by the majority of professional profiles (see Fig. 12.1) and are fundamental to the development of key competences. Thus, both are equally important, but the latter are specific to a particular scientific field or profession and underline specialised abilities. So far, there is no comprehensive set of key competences for bioeconomy professionals in the literature. As sustainability is considered a core principle of the bioeconomy (see Chap. 3), Wiek et al.'s (2011) set of key competences for sustainability provides a sufficient basis for further elaboration.

Figure 12.2 shows the results of a literature review on key competences for sustainability, amalgamating those identified into five key competences, namely, systems-thinking competence, anticipatory competence, normative competence, strategic competence and interpersonal competence (see Box 12.1 for further explanation) (Wiek et al. 2011).
Fig. 12.1 Skills, attitudes and basic competences for the twenty-first century (from World Economic Forum 2015)

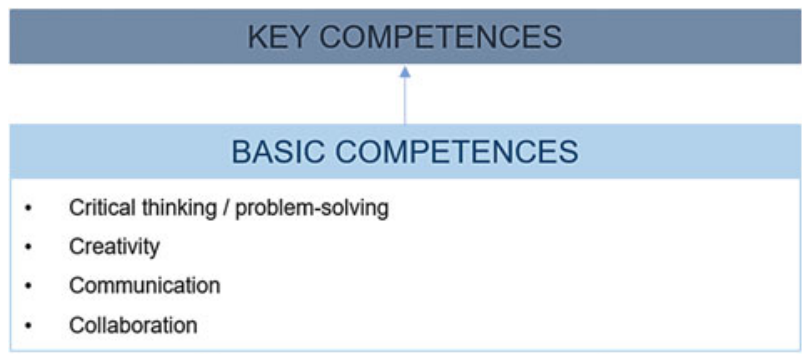

\begin{tabular}{|c|c|}
\hline SKILLS & ATTITUDES \\
\hline $\begin{array}{ll}\text { - } & \text { Literacy } \\
\text { - } & \text { Numeracy } \\
\text { - } & \text { Information and Communication } \\
\text { Technology Literacy } \\
\text { - } & \text { Scientific Literacy } \\
\text { - } & \text { Financial Literacy } \\
\text { - } & \text { Cultural and Civic Literacy }\end{array}$ & $\begin{array}{ll}\text { - } & \text { Curiosity } \\
\text { - } & \text { Initiative } \\
\text { - } & \text { Persistence / Grit } \\
\text { - } & \text { Adaptability } \\
\text { - } & \text { Leadership } \\
\text { - } & \text { Social and Cultural Awareness }\end{array}$ \\
\hline
\end{tabular}




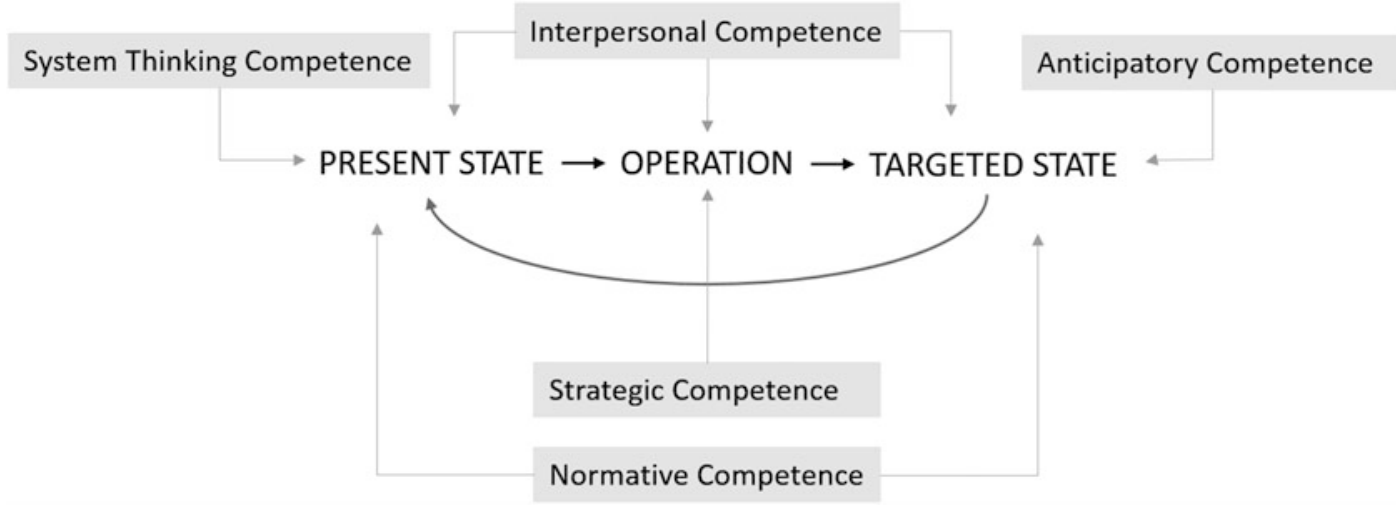

Fig. 12.2 Solving problems_-basic structure (see Fig. 4.1) linked to key competences for sustainability

To explain the scope of the emerging key competences, the basic structure of "solving problems" (see Sect. 4.1.2) can be used. According to this framework, problem solving starts with the characterization of the present state, commonly the description of a complex problem, the inherent system and the involved stakeholders. Therefore, normative competence is the fundament of exploring the problem, and systems-thinking competence is applied to consider the bigger picture. The target state is analysed via anticipatory competence, and normative competence projects values and principles into it. The process towards the target state, the operation, demands a sustainable transition strategy designed with the professional's strategic competence. Across the whole process, interpersonal competence facilitates cooperation and is key to a sustainable solution.

\section{Box 12.1: Key Competences}

for Sustainability (Wiek et al. 2011)

"Systems-thinking competence is the ability to collectively analyse complex systems across different domains (society, environment, economy, etc.) and across different scales (local to global), thereby considering cascading effects, inertia, feedback loops and other systemic features related to sustainability issues and sustainability problem-solving frameworks.” (p. 207)
"Anticipatory competence is the ability to collectively analyse, evaluate, and craft rich "pictures" of the future related to sustainability issues and sustainability problem-solving frameworks." (p. 207)

"Normative competence is the ability to collectively map, specify, apply, reconcile, and negotiate sustainability values, principles, goals, and targets. This capacity enables, first, to collectively assess the (un-)sustainability of current and/or future states of social-ecological systems and, second, to collectively create and craft sustainability visions for these systems." (p. 209)

"Strategic competence is the ability to collectively design and implement interventions, transitions, and transformative governance strategies towards sustainability." (p. 210)

"Interpersonal competence is the ability to motivate, enable, and facilitate collaborative and participatory sustainability research and problem solving. This capacity includes advanced skills in communicating, deliberating and negotiating, collaborating, leadership, pluralistic and trans-cultural thinking, and empathy." (p. 211) 
With respect to interpersonal competence, a differentiation has to be made between typical sustainability experts and bioeconomy professionals. According to Wiek et al. (2011), interpersonal competence is mostly associated with facilitation and communication skills. However, for bioeconomy professionals, interpersonal competence goes beyond the described set and includes a broad knowledge base. Thus, interpersonal competence in the bioeconomy is extended by interdisciplinary competence. Due to the manifold sectors in the bioeconomy, successful collaboration demands strong interdisciplinary competence and an intermediary professional with the ability to understand the subject matter of all stakeholders along the biobased value chain.

\section{T-Shaped Profile}

As indicated in the introduction, complex wicked problems require innovative approaches. The more challenging an issue, the greater the need for the integration of various disciplinary experts and societal stakeholders within comprehensive frameworks to combine diverse knowledge and methods. In order to improve collaboration effectivity, the emergence of shared mental models is beneficial (Madhavan and Grover 1998). As outlined above, this collaborative process may be facilitated by integrative professionals, who use a particular set of competences to set up and support schemes in order to build up trust between different academic and nonacademic players.

\section{(Shared) Mental Model}

Rouse and Morris (1986) define mental models as mechanisms in humans that support the description and explanation of purpose, function and (future) states of systems. Accordingly, mental models allow and shape approaches towards and interaction within systems.

In the context of teamwork, shared mental models refer to knowledge structures within the team (the system), which allow members to explain and describe dynamics in order to coordinate and adapt to changes and tasks. Thus, this does not imply identical mental models of individual team members, but rather compatibility of individual mental models enabling a shared understanding of particular situations (Jonker et al. 2011).

Integrative professionals are ideally also disciplinary experts, educated to incorporate and connect different disciplinary knowledge domains and methods. This is referred to as a T-shaped profile, a term first coined by Marco Iansiti (1993). Metaphorically, the vertical stroke of the T symbolises expertise or deep knowledge in a particular field or discipline. By contrast, the horizontal stroke embodies integrative abilities, allowing $\mathrm{T}$-shaped professionals to act effectively across disciplines and, through this, catalyse, manage and conduct contextualised research and innovation processes. These integrative abilities are based on extensive training of collaboration competences. A professional with a T-shaped profile is aware of the variety of practices and methods as well as mental models employed by different disciplines or professions and understands their strengths and limitations.

The concept may be seen in contrast to the more traditional profiles of I- or A-shaped professionals (Fig. 12.3). Currently, the majority of students graduate with an I-shaped profile, educated to become experts in a particular discipline. This means they have a high level of knowledge and expertise in their field of study. However, I-shaped professionals may be disadvantaged in conducting interdisciplinary team efforts. Deficits in the comprehension of fundamental ideas of other disciplines may impede integration and communication with experts from other areas. By contrast, A-shaped professionals have a high degree of expertise and knowledge in two areas, such as engineering and business, and thus may connect at least two fields efficiently (Karjalainen et al. 2009). 

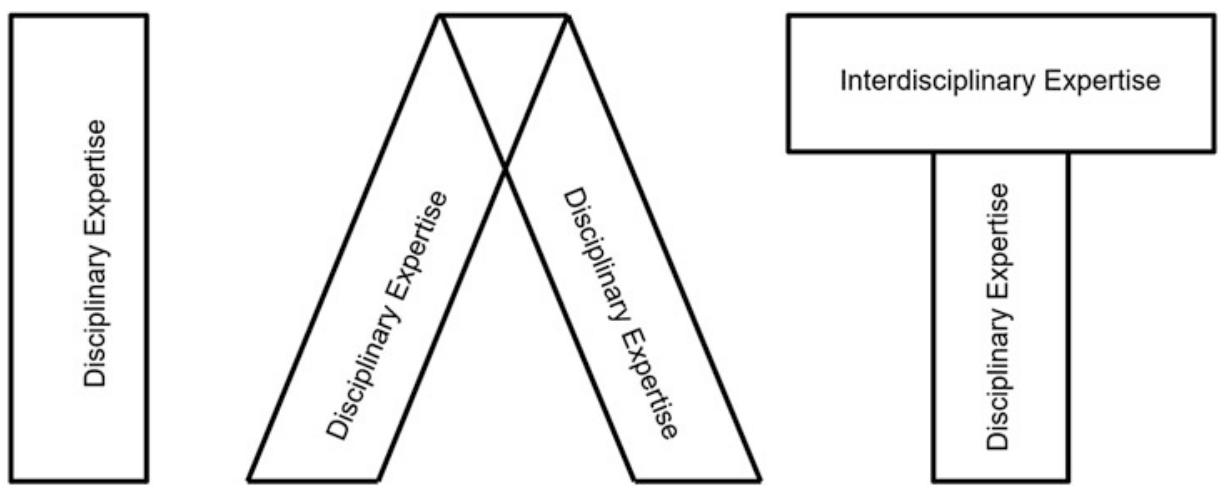

Fig. 12.3 Examples of different professional profiles

The concept of T-shaped profiles goes a step further. These professionals are not only trained to work within multidisciplinary teams but also to facilitate collaboration and connections between experts with various backgrounds. Initially, this idea was derived from "integration teams" in "new product development", as it ideally contributes to more efficient innovation processes (Iansiti 1993). Originally, Iansiti (1993) emphasised the effectiveness of T-shaped profiles in innovation creation through technology integration in the thriving high-tech sector of the 1990s.

Due to the manifold sectors and disciplines the bioeconomy comprises, the T-shaped profile is designated to exploit the bioeconomy's full potential. Players within the bioeconomy have to foster integrative approaches and common goals. Accordingly, intermediary bioeconomy professionals require a $\mathrm{T}$-shaped profile, with expertise in a biobased product-chain-related discipline and broad knowledge in associated disciplines (from primary production to commercialisation, with processes, intermediates and products, see Part II of this book). The ability to understand different scientific languages, by knowing their terminology and methods, enables the mediation between stakeholders and the facilitation of collaboration. This allows bioeconomists to form comprehensive frameworks for the collaboration of research or innovation teams with diverse backgrounds within the bioeconomic sector.
Various stakeholders interact within such frameworks. Thus, knowledge and skills are merged in order to address challenges. In this way, the framework represents a road map for cross-fertilisation and the generation of combinatorial innovations. This means that a set of components may be combined and recombined in new ways to create cutting-edge approaches to (wicked) problems. For this, not only an inclusive and open culture is needed, but also a common understanding of goals must be developed. Therefore, an important task for T-shaped integration specialists is to ensure interdependence of individual goals within the group. Different stakeholders are likely to have different peers, ideas and approaches, which means that the overall team success may be influenced by individual research questions and norms. For this purpose, it is necessary to contextualize and assess the systemic impact of individual actions and knowledge and adjust these goals to the scope of the comprehensive framework. Therefore, integrative professionals in the bioeconomy have to be able to think strategically, requiring a goal-oriented and long-term perspective that has to be in alignment with different disciplinary views and practices.

This profile description of a bioeconomist sounds fairly straightforward. In reality, profiles and roles of bioeconomy professionals are highly diverse. Due to the vast size of the bioeconomic sector, there are numerous job possibilities, and thus there is no one-fits-all profile. 


\subsection{Education for the Bioeconomy}

Most higher education programs, especially university programs, are designed to develop an I-shaped profile (Repko et al. 2017). Graduates have profound expertise in one discipline with a specialisation in a particular research field. However, in recent years, education programs with interdisciplinary curricula have been established, especially in the field of sustainability science, which put emphasis on interdisciplinary research. Bioeconomy is an excellent example of an interdisciplinary research field and thus is predestined for such interdisciplinary education programs. Integrated disciplinary expertise from various knowledge domains connected to the biobased value chain benefits the understanding of the challenges within the bioeconomy and support designated bioeconomy professionals to develop a T-shaped profile.

In general, interdisciplinary study programs combine two or more academic disciplines. Students acquire knowledge in these disciplines, learning methods, concepts and theories, as well as their integration and application to complex research problems, within interdisciplinary teams (Repko et al. 2017). In these teams, shared group processes, differing opinions and approaches are not only tolerated but appreciated (Barth and Burandt 2013). Repko et al. (2017) identified key terms in available definitions of "interdisciplinary studies" and brought these together in the following definition:

Interdisciplinary studies is a cognitive process by which individuals or groups draw on disciplinary perspectives and integrate their insights and modes of thinking to advance their understanding of complex problems with the goal of applying the understanding to a real-world problem. (Repko et al. 2017)

Acquiring the ability to integrate and collaborate is key to the development of interdisciplinary competences (Repko et al. 2017) and thus a main objective of education programs for the bioeconomy. The programs are intended to impart multidisciplinary knowledge and facilitate the development of interdisciplinary competences by means of collaborative curriculum design with innovative learning environments. However, at university level, the coordination of a collaborative curriculum means established disciplinary structures need to be overcome.

The majority of interdisciplinary education programs already established in the field of bioeconomy are master programs (see Box 12.2). With a view to the development of a T-shaped profile, a completed disciplinary bachelor degree would be beneficial. Disciplinary expertise (the vertical stem of the T) already acquired at bachelor level can be extended by interdisciplinary expertise (the horizontal bar of the $\mathrm{T}$ ) in postgraduate studies. In addition, students from different cultural and academic backgrounds create an international and interdisciplinary atmosphere, which facilitates the learning process. However, the students' diverse academic background is also part of the challenge. The first step of an interdisciplinary education program is to establish a common ground by filling knowledge gaps. In the MSc Bioeconomy program at the University of Hohenheim, the students are introduced to natural science concepts, learn basics of agricultural production and become acquainted with economic thinking.

After a common ground has been established, the focus is on the central topic: the bioeconomy. Students learn what the bioeconomy is, why it is both a chance and a challenge and how the shift towards a bioeconomy can be managed. The concept of biobased value chains and the basics of biobased resources, processes and products along these chains are taught. The open curriculum also enables students to develop their own individual profile.

In addition to this multidisciplinary knowledge, education for the bioeconomy places an emphasis on the development of competences, in particular interdisciplinary competence. This is an integral part of the learning process, because competences are seen as learnable but not teachable (Barth and Burandt 2013).

Barth et al. (2007, p. 4) promote a new learning culture which is "enabling-oriented, based on self-organisation and centred on competence". The acquisition of competences is based on the interplay of cognitive (skills) and 
noncognitive (attitude) components. For instance, the development of complex (shared) mental models is a result of cognitive skills. Noncognitive components include value learning, social interaction and reflective skills. Both cognitive and noncognitive components support the development of new competences. The internalisation of new competences is ensured by applying them to multiple contexts via problem-oriented learning (Barth et al. 2007).

In this light, the new learning culture is associated with open learning environments, which means that learning takes place in manifold forms and depends on individual learning styles. Open learning environments facilitate competence development by following three key principles (Barth and Burandt 2013):

1. Self-directed learning aims to stimulate intrinsically motivated learning. For instance, project-based learning or e-learning emphasises the active development of knowledge. It takes students' varying education levels and learning speeds into account. Shallow supervision can guide students towards learning goals.

2. Collaborative learning requests participation and empathy. Project work in groups in particular promotes the development of interdisciplinary competence.

3. Problem-oriented learning considers realworld problems. Therefore, the first two principles are prerequisites for a successful problem-oriented approach, often in collaboration with external stakeholders (e.g. companies).

In the context of learning competences, the interplay between formal and informal learning settings is of particular value (Barth et al. 2007). Study courses with open learning environments offer manifold opportunities for learning in a formal environment. However, informal settings, such as volunteering in a student group, also contribute to the personal learning process and competence development. Here, learning is selfdirected without the assistance of an educator. In some settings, learning may even be incidental, with no previous intention to learn, but an awareness of having learnt something afterwards. The social component of informal learning settings is an additional factor in the promotion of competence development (Schugurensky 2000).

Whether formal or informal, the proactive shaping of a T-shaped profile is a unique selling point for graduates. The innovative potential of the bioeconomy calls for forward-looking collaboration specialists, driven by the goal of the transition towards a biobased economy.

\section{Box 12.2: Examples of Interdisciplinary} Study Programs in the Field of the Bioeconomy

During the last few years, a range of study programs dedicated to the bioeconomy sector has been developed, including Europe's first Bioeconomy degree program at the University of Hohenheim (MSc Bioeconomy). Other examples are MSc Biobased Sciences (Wageningen University); MSc Biobased Materials (Maastricht University); MSc Biocircle (Bioeconomy in the Circular Economy) (University of Bologna, University of Milano-Bicocca, University of Naples Federico II and University of Turin); MSc Management of Bioeconomy, Innovation and Governance (University of Edinburgh) and Master of Engineering Leadership in Green Bio-Products (University of British Columbia). Common elements include the study of entire biobased value chains and the focus on the ecological, social and economic impacts of bioeconomic developments. The general goal is to educate professionals able to identify innovation opportunities through the integration of multi- and interdisciplinary perspectives and diverse knowledge sources. As such, interdisciplinary problem-based group work activities are a common feature of these programs and curriculums. 


\subsection{The Bioeconomist and the Job Market}

The bioeconomy is expected to generate a large number of employment opportunities in the coming years, as documented by various reports and national strategies worldwide (German Bioeconomy Council 2015; European Commission 2015, 2016). With a focus on high added value and creation of new economic activities, the bioeconomy will require skilled professionals along the biobased value chains. Firstly, bioeconomists have an important role in setting up and organising value chains, for which key competences as the ones illustrated in this chapter are necessary (horizontal stroke of the T). Secondly, the various stages of the value chains demand different types of disciplinary expertise (vertical stroke of the $\mathrm{T}$ ).

For instance, the European Bioeconomy Stakeholders Manifesto, issued in 2016 as a result of the 4th Bioeconomy Stakeholder Conference in Utrecht, emphasised connectivity as the new productivity, arguing that "the added value of the bioeconomy lies in the interaction between its diverse areas that provide opportunities for new innovation" (Bioeconomy Stakeholder Conference 2016, p. 4). Based on this, bioeconomic practitioners and researchers with developed key competences (see Sect. 12.2) act as connectors and catalysers of bioeconomy. These roles are to be performed in managerial and leading positions in private, public and thirdsector organisations in the field of research and development, rural development, advisory services, sustainability-oriented institutions and policy-making bodies. A special role for bioeconomist due to the T-shape profile is the leading of interdisciplinary teams and projects, performing as a project manager in the context of sustainability and bioeconomy.

Particular career development options are offered by start-ups, which are considered key drivers of innovation in the bioeconomy. The design and implementation of bioeconomy governance structures and policies through the engagement of various players are enriched by the involvement of bioeconomy professionals. In this manner, the understanding, assessing and addressing of possible conflicts and trade-offs are enhanced (German Bioeconomy Council 2015). This supporting role is also to be performed within the knowledge and innovation system (KIS) introduced by the European Commission as a basis for fostering the bioeconomy (Kovacs 2015).

Due to the novelty of interdisciplinary programs for the education of bioeconomists, there is as yet no empirical information on the positions they may hold. This is confirmed by the Global Bioeconomy Summit Manifesto, which states the need "to initiate a dialogue among stakeholders regarding the knowledge, skills and competencies, which will be crucial for implementing the bioeconomy, and to promote mutual capacity building efforts" (German Bioeconomy Council 2015, p. 8). Some thoughts and insights from selected bioeconomy experts with regard to the job market and the role of bioeconomy professionals are presented in the Box 12.3, as a mean of building up this dialogue.

\section{Box 12.3: Excursus Box: Insights from} Bioeconomy Professionals

Prof. Dr. Werner Kunz: "In a world of growing complexity, easy solutions are an illusion. In the future, entrepreneurial success and a respectful treatment of the global environment will be interdependent. This challenge requires the connection of various disciplines and, consequently, demands a more comprehensive education and training of future professionals. Ecologists have to be able to communicate with economists and, in turn, both need to have the confidence of engineers and technicians. Life Cycle Assessments will be as important as business plans and the associated process technologies.

With this is mind, I am convinced of the necessity of interface managers ("Schnittstellenmanager"), who will 


\section{Box 12.3 (continued)}

connect relevant players along the value chain. Remarkable progress can already be observed in particular sectors of the bioeconomy. However, at the same time, a deficit in connectivity is impairing more comprehensive development and innovation.

For this reason, I aspire to more interdisciplinary programs in Germany and the entire world. These education programs ought to be committed to the connection of highly complex disciplines and fields in holistic approaches. This will be fundamental for the future and beneficial for society, industry and environment."

Prof. Dr. Werner Kunz is Chair of Physical and Theoretical Chemistry at Regensburg University, where his research is dedicated to solution chemistry. He has performed numerous projects with industrial partners and runs his own company in the field of the bioeconomy (SKH GmbH).

Christiane Grefe: "Education-but for which bioeconomy? There are so many different definitions of what bioeconomy is and what it could or should be (and so many controversies even about whether the term makes any sense at all), that a "bioeconomy professional" cannot be described without further clarification of what his/her role should be tailored to.

In my view, the term bioeconomy must go beyond changing the resource basis from fossil to renewable, as well as beyond applying genome editing to different industrial, medical or plant breeding purposes; it must also go beyond producing "more with less" or creating innovative value chains in order to achieve "green" economic growth. The added value of the concept is to consider all this in its interdependencies and trade-offs in the context of our planetary boundaries and a just distribution of all natural resources.
Bioeconomy should be envisaged as a true circular economy, better: as circular economies, which are specific to the ecological, social, and technological diversity of regional and local conditions.

Future "bioeconomy professionals" should therefore not only have knowledge of innovative technologies, as promoted by most governments and industries. They should also understand ecosystems, their cultural aspects included. And they should have training in communication and dialogue capabilities.

The latter should be a priority because a lot of conflicts will have to be resolved. And, even more important: opportunities for efficient uses and re-uses will not be discovered without organising intense cooperation-and thus: communication. A bioeconomy respectful of given natural or cultural limits will only develop fruitfully if industries and city governments, scientists and professionals, citizens and environmentalists all work closely together, coordinated by bioeconomy experts."

Christiane Grefe is a ZEIT journalist and author of the book Global Gardening-Biökonomie: neuer Raubbau oder Wirtschaftsform der Zukunft?, Antje Kunstmann Verlag, München, 2016.

Markus Frank: "Being a professional in the bioeconomic sector requires, besides deep knowledge in one field of expertise, competences in managing scarce biobased resources, and thus, implies fundamental understanding of sustainability. Therefore, education for future professionals in this field should be designed to develop best practices for integrating sustainable management concepts into work routines.

In this context, two concepts are of particular interest. First, life-cycle thinking enables impacts along the entire value chains to be reflected upon, and the 


\section{Box 12.3 (continued)}

displacement of negative environmental, social, and economic impacts to be avoided. Second, learning about stakeholder theory and the engagement of stakeholders promotes the mutual understanding of different players' interests and needs. Both approaches comprise key competences for project managers in the area of biobased economies in order to analyse trade-offs and deal with complex challenges. The learning of these key competences demands practically oriented education environments; a shift from classroom teaching towards project-based social learning through working on reallife problems. In this context, collaboration with companies, political or regulatory stakeholders, NGOs and associations can be of benefit. Supplementary international and interdisciplinary study programs on the science behind project management, strategy development and implementation, marketing, and financial valuation as well as stakeholder engagement should help students to transfer what they have learnt to other case studies in their professional life.

Clearly, there is a demand in the job market for graduates with such competences. However, it is crucial for the employer to also see a "basic skill set" (e.g. in business, natural science, agronomy, or engineering) beside the special focus on bioeconomy and sustainability management: Most, if not all, professionals will be exposed to very different areas inside the organisation.

In a nutshell, the unique value proposition of a graduate combines deep knowledge in the field of biobased value chains, the concepts of life-cycle thinking and stakeholder engagement with a profound background in project management, team working and strategic thinking. To achieve this, project-based learning addressing real-world problems should be emphasised in the curriculum."

Markus Frank works for the department "Global Sustainability \& Product Stewardship Crop Protection" at BASF SE. He holds a PhD in Biology and a MBA from Surrey Business School. At the University of Hohenheim, he supervises students within the module "Projects in Bioeconomic Research".

Dr. Michael Schweizer: "As a company within the biobased sector, we recognise the importance of the development of new curricula. Professionals for biobased companies should be characterised by a special set of skills. I would like to emphasize the additional benefit of graduates capable of understanding both the technical and economic dimension of products or services. This is of outstanding relevance in small and medium enterprises (SMEs) in particular, as the conversant use of economic figures and also technological and ecological data is a prerequisite for successful communication with costumers. Correspondingly, employees should ideally have a mindset that allows them to understand terms and mental models of key players active in areas related to the biobased company.

Especially in small enterprises, employees are in constant touch with other disciplinary specialists, as a clear department structure is often not given, and companies are less hierarchically structured. In this context, work is highly dependent on group efforts and therefore social ability and teamwork efficiency are indispensable skills that should not be underestimated. Accordingly, abilities such as team leading, project management and presentation skills are a vital part of relevant education programs.

However, even more important for bioeconomy professionals is openness and 


\section{Box 12.3 (continued)}

proactivity; characteristics I experienced during my contact with Hohenheim bioeconomy students. These qualities should be further strengthened by the education environment. This could be achieved by project learning in collaboration with companies, and other additional activities such as this textbook, visits to conferences, and the organisation of extracurricular lectures. Following this approach, graduates should be well prepared for a career in SMEs, as real-world challenges and everyday work routines are already part of their expertise."

Dr. Michael Schweizer is research manager in the field of biobased composites for Tecnaro GmbH, Ilsfeld. Before joining the company, Mr. Schweizer studied chemistry and worked as a research scientist at the German Institutes of Textile and Fiber Research in Denkendorf (DITF).

\section{Review Questions}

- Why collaboration is considered as a central aspect to address wicked problems?

- Can someone with a deep disciplinary formation acquire the key competences illustrated in this chapter? How can this happen?

- What are possible opportunities and hurdles of a T-shaped profile with a stronger horizontal than vertical stroke and vice versa?

- Why would a company employ a bioeconomist? How can such professional add value and what roles would he/she performs?

\section{References}

Ananiadou K, Claro M (2009) 21st century skills and competences for new millennium learners in OECD countries. OECD Educ Work Pap. https://doi.org/10. $1787 / 218525261154$

Barth M, Burandt S (2013) Adding the "e-" to learning for sustainable development: challenges and innovation. Sustainability 5:2609-2622. https://doi.org/10.3390/ su5062609
Barth M, Godemann J, Rieckmann M et al (2007) Developing key competencies for sustainable development in higher education. Int J Sustain High Educ 8:416-430. https://doi.org/10.1108/146763707 10823582

Batie SS (2008) Wicked problems and applied economics. Am J Agric Econ 90:1176-1191. https://doi.org/ 10.1111/j.1467-8276.2008.01202.x

Dentoni D, Bitzer V (2015) The role(s) of universities in dealing with global wicked problems through multistakeholder initiatives. J Clean Prod 106:68-78. https://doi.org/10.1016/j.jclepro.2014.09.050

European Comission (2015) Sustainable agriculture, forestry and fisheries in the bioeconomy - a challenge for europe. 4th SCAR Foresight Exercise

European Comission (2016) European bioeconomy stakeholders manifesto, building blocks. Bioeconomy Utrecht 2016 - 4th Stakeholder's Conference

German Bioeconomy Council (2015) Bioeconomy policy (Part II)-Synopsis of national strategies around the world, pp 1-146

Head B, Xiang W (2016) Why is an APT approach to wicked problems important? Landsc Urban Plan 154:4-7. https://doi.org/10.1016/j.landurbplan.2016. 03.018

Iansiti M (1993) Real-world R\&D: jumping the product generation gap. Harv Bus Rev 71:138-147

Innes JE, Booher DE (2016) Collaborative rationality as a strategy for working with wicked problems. Landsc Urban Plan 154:8-10. https://doi.org/10. 1016/j.landurbplan.2016.03.016

Jonker CM, Van Riemsdijk MB, Vermeulen B (2011) Shared mental models. In: De Vos M, Fornara N, Pitt JV, Vouros G (eds) Coordination, organizations, institutions, and norms in agent systems VI. Springer, Berlin, pp 132-151

Karjalainen TM, Koria M, Salimäki M (2009) Educating T-shaped design, business and engineering professionals. In: Proceedings of the 19th CIRP design conference, 30-31 Mar 2009

Kovacs B (ed) (2015) Sustainable agriculture, forestry and fisheries in the bioeconomy. In: Standing Committee on Agricultural Research 4th Foresight Exercise

Madhavan R, Grover R (1998) From embedded knowledge to embodied knowledge: new product development as knowledge management. J Mark 62:1-12

OECD (2005) The definition and selection of key competencies-executive summary

Pacanowsky M (1995) Team tools for wicked problems. Organ Dyn 23:36-51. https://doi.org/10.1016/00902616(95)90024-1

Polk M (2015) Transdisciplinary co-production: designing and testing a transdisciplinary research framework for societal problem solving. Futures. https://doi.org/ 10.1016/j.futures.2014.11.001

Repko AF, Szostak R, Buchenberger MP (2017) Identifying relevant disciplines and gathering information about the problem. In: Introduction to interdisciplinary studies, 2nd edn. Sage, Thousand Oaks, CA 
Rittel HWJ, Webber MM (1973) Dilemmas in a general theory of planning. Policy Sci 4:155-169. https://doi. org/10.1007/BF01405730

Rouse WB, Morris NM (1986) On looking into the black box: prospects and limits in the search for mental models. Psychol Bull 100:349-363. https://doi.org/ 10.1037/0033-2909.100.3.349

Rychen DS, Salganik LH (2000) Definition and selection of key competencies - a contribution of the OCDE program definition and selection of competencies: theoretical and conceptual foundations
Schneidewind U, Singer-Brodowski M, Augenstein K et al (2016) Pledge for a transformative science: a conceptual framework. Wuppertal Pap 28. ISSN: 0949-5266

Schugurensky D (2000) The forms of informal learning: towards a conceptualization of the field

WEF (2015) New vision for education unlocking the potential of technology

Wiek A, Withycombe L, Redman C (2011) Key competencies in sustainability: a reference framework for academic program development. Sustain Sci 6:203218. https://doi.org/10.1007/s11625-011-0132-6

Open Access This chapter is licensed under the terms of the Creative Commons Attribution 4.0 International License (http://creativecommons.org/licenses/by/4.0/), which permits use, sharing, adaptation, distribution and reproduction in any medium or format, as long as you give appropriate credit to the original author(s) and the source, provide a link to the Creative Commons license and indicate if changes were made.

The images or other third party material in this chapter are included in the chapter's Creative Commons license, unless indicated otherwise in a credit line to the material. If material is not included in the chapter's Creative Commons license and your intended use is not permitted by statutory regulation or exceeds the permitted use, you will need to obtain permission directly from the copyright holder. 